Research Paper

\title{
Surgery plus chemotherapy improves survival of patients with extremity soft tissue leiomyosarcoma and metastasis at presentation
}

\author{
Sheng-Jun Qian ${ }^{*}$, Jia-Qi Wu1 ${ }^{*}$, Zhan Wang $1^{*}$, Bo Zhang ${ }^{2^{\bowtie}}$ \\ 1. Centre for Orthopaedic Research, Orthopedics Research Institute of Zhejiang University, Department of Orthopaedics, The Second Affiliated Hospital, \\ Zhejiang University School of Medicine, 88 Jiefang Road, Hangzhou, Zhejiang 310000, P.R. China \\ 2. Department of Orthopedics, Ningbo No.2 Hospital, 41 North West Street, Ningbo, Zhejiang 315010, P.R. China \\ * Sheng-Jun Qian, Jia-Qi Wu, and Zhan Wang contributed equally to this work. \\ $\triangle$ Corresponding author: Bo Zhang, Department of Orthopedics, Ningbo No.2 Hospital, 41 North West Street, Ningbo, Zhejiang 315010, P.R. China, E-mail: \\ Zhangbozhoushan@163.com \\ (c) Ivyspring International Publisher. This is an open access article distributed under the terms of the Creative Commons Attribution (CC BY-NC) license \\ (https://creativecommons.org/licenses/by-nc/4.0/). See http://ivyspring.com/terms for full terms and conditions.
}

Received: 2018.09.11; Accepted: 2019.04.07; Published: 2019.05.21

\begin{abstract}
Purpose: Extremity soft tissue leiomyosarcoma (LMS) with metastasis is a rare disease with a poor prognosis. The purpose of our study was to define clinical features of extremity soft tissue LMS with metastasis as well as to identify multivariable predictors of survival.

Methods: During 1973-2015, 239 patients with metastatic extremity soft tissue LMS were identified from the Surveillance, Epidemiology, and End Results (SEER) program database. The prognostic analysis was performed using the Kaplan-Meier method and a Cox proportional hazards regression model.

Results: This group comprised 126 females $(52.7 \%)$ and 113 males $(47.3 \%)$, whose ages ranged from 8 to 95 years (median 67 years). The overall survival (OS) and cancer-specific survival (CSS) rates of the entire group at 3 years were $22.6 \%$ and $23.4 \%$, respectively. The median OS and CSS were $14.0 \pm 1.5$ and $15.0 \pm 2.3$ months, respectively. Multivariate analysis revealed that tumor size $>10$ $\mathrm{cm}$, no surgery and no chemotherapy were independent risk factors of decreased OS and CSS. Radiotherapy was not significantly associated with OS or CSS.

Conclusion: Extremity soft tissue LMS patients who present with metastasis at diagnosis had a poor prognosis. Patients who performed surgery for primary tumors and chemotherapy had a better chance for prolonged survival.
\end{abstract}

Key words: Leiomyosarcoma, metastasis at presentation, survival, prognostic factor, treatment

\section{Introduction}

Soft tissue leiomyosarcoma (LMS) is a rare malignant mesenchymal neoplasm which arises from smooth muscle [1]. LMS occur predominantly in the retroperitoneum or intraabdominal sites and is less common in the extremities. Extremity LMS comprised about $10 \%$ to $15 \%$ of extremity sarcomas, and it arose predominantly from blood vessels, with a preference for the lower limb [2-4]. Extremity LMS tend to achieve a better prognosis than uterine, retroperitoneal, and major vessel LMS [4-6]. However, patients with soft tissue sarcoma (STS) and metastasis usually have a poor prognosis, and the median survival is 12 months [7-9]. Current treatments for patients with STS include surgery, radiation and systemic chemotherapy. However, the treatment for metastatic LMS remains a challenge, as curative treatment for metastatic disease is rare.

To obtain deeper insight into soft tissue extremity LMS and metastasis at diagnosis, we analyzed all patients from 1973 to 2015 in the 
Surveillance, Epidemiology, and End Results (SEER) program database of the National Cancer Institute. This was a large-scale study of patients with soft tissue extremity LMS and metastasis at diagnosis that aimed to determine the predictors of survival.

\section{Materials and Methods}

\section{Patient population}

A total of 256 patients diagnosed with extremity soft tissue LMS and metastasis at initial presentation were identified from 1973 to 2015. All patient data were obtained using the case-listing session procedure from the SEER program. This study followed standard guidelines and was approved by the local Ethics Committee.

First, the International Classification of Diseases for Oncology, $3^{\text {rd }}$ edition (ICD-O-3) was used to identify patients with extremity soft tissue LMS (ICD-O-3 histologic type: 8890, 8891 and 8896; ICD-O-3 site code: C49.1 and C49.2), using the case-listing procedure. The flow chart for selection of study population was shown in Figure 1. Only patients with metastatic disease were enrolled, by reference to the tumor stage at diagnosis. LMS arising from the skeletal locations was excluded. All patient diagnoses were confirmed histologically, based either on biopsy results or the surgical specimen. Four patients diagnosed only on the basis of the clinical presentation, or according to the radiography, or unknown were excluded. Seven patients with unknown therapy were excluded. Six patients with survival time less than one month were also excluded. Data extracted from the SEER database included age, gender, year of diagnosis, location, tumor grade, tumor stage, tumor size, surgical treatment, radiation treatment, chemotherapy, cause of death, and survival time. Surgery or radiation treatment for tumors in our study refers to treatment for local primary tumors.

\section{Statistical methods}

The SPSS statistical software (version 22.0) and Microsoft Excel 2017 were used to analyze the data. Overall survival (OS) was defined as the time from diagnosis to death from any cause, and cancer-specific survival (CSS) was defined as the time from diagnosis to death specific to the cancer-related diagnosis. Univariate analysis was performed using the Kaplan-Meier method with the log-rank test. Survival curves were generated by the Kaplan-Meier method and compared by log-rank test. Observations were censored if the patient was alive at the time of the last follow-up. Risk factors with $\mathrm{p}<0.1$ in univariate analysis were included in the multivariate analysis. Multivariate analysis was performed to determine the independent predictors of OS and CSS with Cox proportional-hazard regression analyses. The hazard ratios (HRs) and corresponding 95\% confidence intervals (CIs) were calculated to show the effect of factors on OS and CSS. Differences were deemed statistically significant if the $p<0.05$.

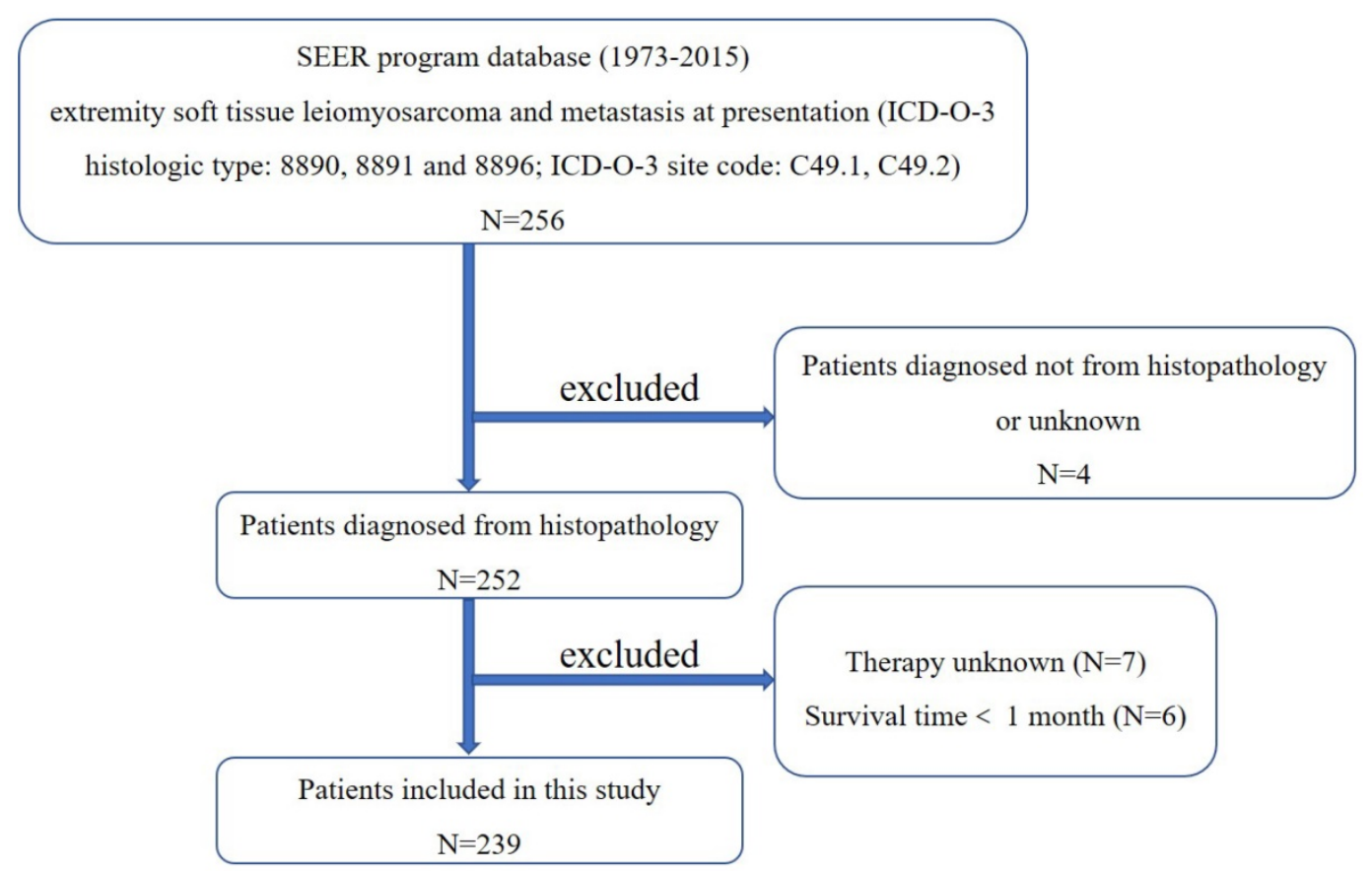

Figure 1. The flow chart for selection of study population. (Abbreviations: SEER, Surveillance, Epidemiology, and End Results; ICD-O-3, international classification of diseases for oncology, 3rd edition.) 


\section{Results}

\section{Clinical characteristics of the 239 patients with} metastatic extremity soft tissue LMS

From 1973 to 2015, data for a total of 239 patients with metastatic extremity soft tissue LMS who met the inclusion criteria were collected from the SEER database. Demographic and clinical characteristics of patients are listed in Table 1.

Table 1. Demographic and clinical characteristics of 239 patients with soft tissue extremity leiomyosarcoma and metastasis at presentation identified in the SEER database from 1973 to 2015

\begin{tabular}{|c|c|}
\hline Category & Value \\
\hline Mean age (years) & 65 \\
\hline Median age (years) & 67 \\
\hline \multicolumn{2}{|l|}{ Age(years) } \\
\hline$<60$ & $84(35.1 \%)$ \\
\hline$\geq 60$ & $155(64.9 \%)$ \\
\hline \multicolumn{2}{|l|}{ Gender } \\
\hline Female & $126(52.7 \%)$ \\
\hline Male & $113(47.3 \%)$ \\
\hline \multicolumn{2}{|l|}{ Year of diagnosis } \\
\hline$<2000$ & $60(25.1 \%)$ \\
\hline$\geq 2000$ & $179(74.9 \%)$ \\
\hline \multicolumn{2}{|l|}{ Location } \\
\hline Upper limb & $35(14.6 \%)$ \\
\hline Lower limb & $204(85.4 \%)$ \\
\hline \multicolumn{2}{|l|}{ Tumor size } \\
\hline$<5 \mathrm{~cm}$ & $34(14.2 \%)$ \\
\hline $5-10 \mathrm{~cm}$ & $66(27.6 \%)$ \\
\hline$>10 \mathrm{~cm}$ & $80(33.5 \%)$ \\
\hline Unknown & $59(24.7 \%)$ \\
\hline \multicolumn{2}{|l|}{ Tumor Grade } \\
\hline Low & $30(12.6 \%)$ \\
\hline High & $149(62.3 \%)$ \\
\hline Unknown & $60(25.1 \%)$ \\
\hline \multicolumn{2}{|l|}{ Surgical treatment } \\
\hline Yes & $142(59.4 \%)$ \\
\hline No & $97(40.6 \%)$ \\
\hline \multicolumn{2}{|l|}{ Radiation treatment } \\
\hline Yes & $92(38.5 \%)$ \\
\hline No & $147(61.5 \%)$ \\
\hline \multicolumn{2}{|l|}{ Chemotherapy } \\
\hline Yes & $138(57.7 \%)$ \\
\hline No & $101(42.3 \%)$ \\
\hline \multicolumn{2}{|l|}{ Deceased } \\
\hline Yes & $207(86.6 \%)$ \\
\hline No & $32(13.4 \%)$ \\
\hline 3-year OS rate & $22.6 \%$ \\
\hline 3-year CSS rate & $23.4 \%$ \\
\hline 5-year OS rate & $11.3 \%$ \\
\hline 5-year CSS rate & $11.3 \%$ \\
\hline
\end{tabular}

The mean and median patient ages at diagnosis were 65 and 67 years, respectively. More than half $(n=126,52.7 \%)$ of the patients were female. More than two-thirds of the cases were diagnosed after 2000. In terms of location, $14.6 \%$ tumors were located in the upper limbs, and $85.4 \%$ in lower limbs.149 (62.3\%) of the tumors were categorized as high grade. Information on the tumor size was available in $75.3 \%$ cases, and was categorized into four groups. In addition, 142 (59.4\%) patients received local surgery, $92(38.5 \%)$ patients received radiation treatment, and $138(57.7 \%)$ patients received chemotherapy. Ultimately, 207 patients $(86.6 \%)$ died, of whom 152 died of this cancer. The 3- and 5-year OS rates of the entire cohort were $22.6 \%$ and $11.3 \%$, respectively. The 3 - and 5-year CSS rates were $23.4 \%$ and $11.3 \%$, respectively (Table 1). The median OS and CSS of this cohort were $14.0 \pm 1.5$ and $15.0 \pm 2.3$ months, respectively (Table 2 ).

Table 2. Median survival data (month) of 239 patients with soft tissue extremity leiomyosarcoma and metastasis at presentation

\begin{tabular}{|c|c|c|c|c|}
\hline Category & OS & $95 \% \mathrm{CI}$ & CSS & $95 \% \mathrm{CI}$ \\
\hline Overall & $14.0 \pm 1.5$ & $11.0-17.0$ & $15.0 \pm 2.3$ & $10.5-19.5$ \\
\hline \multicolumn{5}{|l|}{ Age(years) } \\
\hline$<60$ & $22.0 \pm 3.4$ & $15.3-28.7$ & $25.0 \pm 3.5$ & $18.2-31.8$ \\
\hline$\geq 60$ & $10.0 \pm 1.4$ & $7.2-12.8$ & $11.0 \pm 1.4$ & $8.2-13.8$ \\
\hline \multicolumn{5}{|l|}{ Gender } \\
\hline Female & $14.0 \pm 2.7$ & $8.7-19.3$ & $16.0 \pm 3.9$ & $8.3-23.7$ \\
\hline Male & $14.0 \pm 2.1$ & $9.9-18.1$ & $15.0 \pm 2.6$ & $10.0-20.0$ \\
\hline \multicolumn{5}{|c|}{ Year of diagnosis } \\
\hline$<2000$ & $13.0 \pm 2.8$ & $7.6-18.4$ & $13.0 \pm 3.0$ & $7.1-18.9$ \\
\hline$\geq 2000$ & $15.0 \pm 2.0$ & $11.1-18.9$ & $16.0 \pm 2.6$ & $10.9-21.1$ \\
\hline \multicolumn{5}{|l|}{ Location } \\
\hline Upper limb & $9.0 \pm 1.2$ & $6.7-11.3$ & $9.0 \pm 2.0$ & $5.0-13.0$ \\
\hline Lower limb & $15.0 \pm 1.9$ & $11.2-18.8$ & $16.0 \pm 3.2$ & $9.6-22.4$ \\
\hline \multicolumn{5}{|c|}{ Tumor grade ${ }^{a}$} \\
\hline Low & $13.0 \pm 5.0$ & $3.2-22.8$ & $13.0 \pm 3.2$ & $6.7-19.3$ \\
\hline High & $15.0 \pm 1.4$ & $12.2-17.8$ & $15.0 \pm 2.6$ & 9.9-20.1 \\
\hline \multicolumn{5}{|l|}{ Tumor size } \\
\hline$<5 \mathrm{~cm}$ & $28.0 \pm 9.3$ & $9.8-46.2$ & $19.0 \pm 14.9$ & $0.0-48.1$ \\
\hline $5-10 \mathrm{~cm}$ & $18.0 \pm 3.2$ & $11.7-24.3$ & $19.0 \pm 2.7$ & $13.7-24.3$ \\
\hline$>10 \mathrm{~cm}$ & $11.0 \pm 1.7$ & $7.7-14.3$ & $12.0 \pm 2.0$ & $8.0-16.0$ \\
\hline \multicolumn{5}{|c|}{ Surgical treatment } \\
\hline Yes & $17.0 \pm 3.1$ & $10.8-23.2$ & $17.0 \pm 3.4$ & $10.4-23.6$ \\
\hline No & $11.0 \pm 2.0$ & $7.1-14.9$ & $11.0 \pm 3.1$ & $4.8-17.2$ \\
\hline \multicolumn{5}{|c|}{ Radiation treatment } \\
\hline Yes & $15.0 \pm 2.4$ & 10.4-19.6 & $13.0 \pm 2.1$ & 8.9-17.1 \\
\hline No & $14.0 \pm 2.0$ & $10.0-18.0$ & $19.0 \pm 4.7$ & $9.9-28.1$ \\
\hline \multicolumn{5}{|c|}{ Chemotherapy } \\
\hline Yes & $22.0 \pm 2.9$ & $16.3-27.7$ & $23.0 \pm 3.5$ & 16.1-29.9 \\
\hline No & $8.0 \pm 1.0$ & $6.0-10.0$ & $7.0 \pm 1.5$ & $4.2-9.8$ \\
\hline
\end{tabular}

a: Low: Grade I (well differentiated) and Grade II (moderately differentiated); High: Grade III (poorly differentiated) and Grade IV (undifferentiated anaplastic). OS: overall survival, CSS: cancer-specific survival.

\section{Univariate analyses of variables associated with OS or CSS in patients with metastatic extremity soft tissue LMS}

Univariate analyses were shown in Table 3. Our study revealed that gender, year of diagnosis, location, tumor grade, and radiation treatment were not associated with either OS or CSS. Age $\geq 60$ years was significantly associated with decreased OS and CSS (Table 2 and 3). Tumor size $>10 \mathrm{~cm}$ was significantly associated with a decreased OS and CSS (Table 2 and 3). Surgical treatment has been significantly associated with an increased OS and CSS (Fig. 2). Similarly, patients who received chemotherapy had significantly better OS and CSS than those who did not (Fig. 3). 
Table 3. Univariate analysis of variables in 239 patients with soft tissue extremity leiomyosarcoma and metastasis at presentation

\begin{tabular}{lll}
\hline Category & $\begin{array}{l}\text { OS (Log-rank p } \\
\text { value) }\end{array}$ & $\begin{array}{l}\text { CSS (Log-rank p } \\
\text { value) }\end{array}$ \\
\hline Age at diagnosis $(<60 \mathrm{vs} \geq 60)$ & 0.002 & 0.001 \\
Gender (female vs male) & 0.875 & 0.605 \\
Year of diagnosis (<2000 vs $\geq 2000)$ & 0.909 & 0.440 \\
Location (upper limb vs lower limb) & 0.064 & 0.162 \\
Tumor gradea (low vs high) & 0.824 & 0.713 \\
Tumor size & 0.044 & 0.082 \\
$>10 \mathrm{~cm}$ vs $<5 \mathrm{~cm}$ & 0.008 & 0.020 \\
$>10 \mathrm{~cm}$ vs 5-10 cm & 0.132 & 0.114 \\
$5-10 \mathrm{~cm}$ vs $<5 \mathrm{~cm}$ & 0.188 & 0.191 \\
Surgical treatment (yes vs no) & $<0.001$ & 0.004 \\
Radiation treatment (yes vs no) & 0.853 & 0.146 \\
Chemotherapy (yes vs no) & $<0.001$ & $<0.001$ \\
\hline
\end{tabular}

a: Low: Grade I (well differentiated) and Grade II (moderately differentiated); High: Grade III (poorly differentiated) and Grade IV (undifferentiated anaplastic).

OS: overall survival; CSS: cancer-specific survival

\section{Multivariate analysis of independent predictors of OS or CSS in patients with metastatic extremity soft tissue LMS}

Multivariate analyses were employed to identify independent risk factors for survival in patients with metastatic extremity soft tissue LMS (Table 4). On multivariate analysis of all patients, tumor size $>10$ $\mathrm{cm}$, no surgery and no chemotherapy were found to be independent risk factors of decreased OS and CSS.
Older age, male, high tumor grade, and radiation treatment failed to become an independent risk factor for either OS or CSS.

Table 4. Multivariate analysis for OS and CSS for 239 patients with soft tissue extremity leiomyosarcoma and metastasis at presentation

\begin{tabular}{|c|c|c|c|c|}
\hline Variable & OS & & CSS & \\
\hline & $\begin{array}{l}\text { Hazard Ratio } \\
(95 \% \text { CI) }\end{array}$ & P value & $\begin{array}{l}\text { Hazard Ratio } \\
(95 \% \text { CI })\end{array}$ & $P$ value \\
\hline \multicolumn{5}{|l|}{ Age(years) } \\
\hline$<60$ & 1 & & 1 & \\
\hline$\geq 60$ & $1.237(0.912-1.678)$ & 0.171 & $1.371(0.967-1.944)$ & 0.076 \\
\hline \multicolumn{5}{|l|}{ Location } \\
\hline Upper limb & 1 & & - & \\
\hline Lower limb & $0.701(0.471-1.041)$ & 0.078 & - & - \\
\hline \multicolumn{5}{|l|}{ Tumor size } \\
\hline$<5 \mathrm{~cm}$ & 1 & & 1 & \\
\hline $5-10 \mathrm{~cm}$ & $1.492(0.930-2.392)$ & 0.097 & $1.466(0.839-2.563)$ & 0.179 \\
\hline$>10 \mathrm{~cm}$ & $2.219(1.384-3.558)$ & 0.001 & $2.223(1.256-3.934)$ & 0.006 \\
\hline \multicolumn{5}{|l|}{$\begin{array}{l}\text { Surgical } \\
\text { treatment }\end{array}$} \\
\hline Yes & 1 & & 1 & \\
\hline No & $2.087(1.536-2.835)$ & $<0.001$ & $2.007(1.411-2.855)$ & $<0.001$ \\
\hline \multicolumn{5}{|c|}{ Chemotherapy } \\
\hline Yes & 1 & & 1 & \\
\hline No & $2.089(1.550-2.814)$ & $<0.001$ & $2.254(1.585-3.205)$ & $<0.001$ \\
\hline
\end{tabular}

OS: overall survival; CSS: cancer-specific survival.
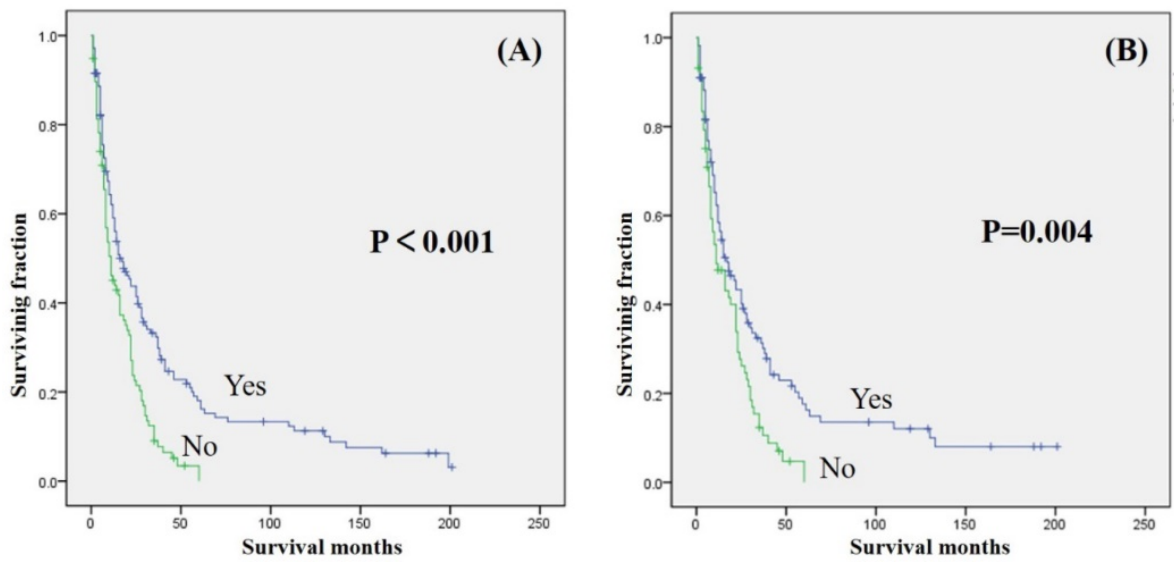

Figure 2. Kaplan-Meier method estimated OS (A) and CSS (B) in patients with extremity soft tissue leiomyosarcoma and metastasis at presentation stratified by surgery.
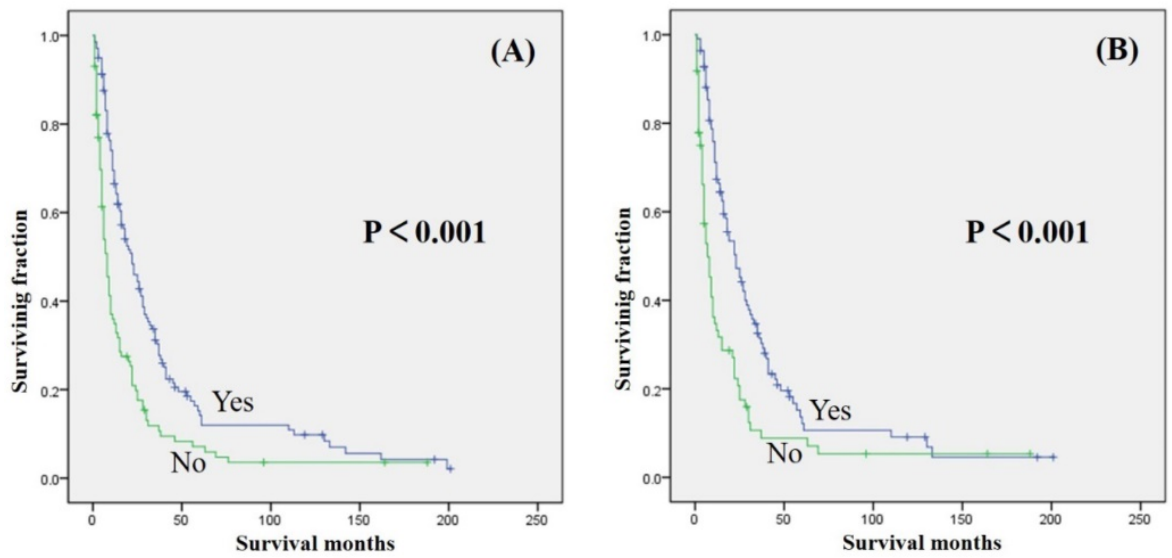

Figure 3. Kaplan-Meier method estimated OS (A) and CSS (B) in patients with extremity soft tissue leiomyosarcoma and metastasis at presentation stratified by chemotherapy. 


\section{Discussion}

Leiomyosarcoma is one of the most common STSs, accounting for $10 \%-20 \%$ of all newly diagnosed STSs [10]. Soft tissue LMS is rarely seen in the extremities, comprising about $10 \%-15 \%$ of extremity sarcomas [2]. Extremity soft tissue LMS can metastasize to distant sites such as lungs, bones, and other organs at an early stage [11]. Despite intensive treatment, patients with extremity STS and metastasis usually had a poor prognosis [12-14]. Krishnan et al. [13] reported that the median survival of patients with extremity STS and metastasis at diagnosis after surgery was $22 \pm 4.1$ months. The 2- and 5-year survival rates were $45.6 \%$ and $18.0 \%$. In our study, the median OS and CSS of this cohort were $14.0 \pm 1.5$ and $15.0 \pm 2.3$ months, respectively. Both the 5-year OS and CSS rates of the entire cohort were $11.3 \%$, suggesting that patients with extremity soft tissue LMS and metastasis had worse prognosis than other types.

There is a significant unmet need to improve their outcome further. Because cases of extremity soft tissue LMS and metastasis at presentation are rare, few studies have documented the prognosis of this group. Our study is the first to describe the demographic information of such patients and explore possible predictors of survival using the SEER database. The specific roles of chemotherapy and radiation treatment in this group were also explored in our study.

The mean and median age at diagnosis of our cohort was 65 and 67 years, respectively, with a similar ratio of male to female. Univariate analyses of this cohort showed that gender was not associated with significant differences in either OS or CSS, in accordance with other research results $[12,15]$. The survival of patients diagnosed before 2000 years and after 2000 years had no significant difference. Many studies found age at diagnosis was significantly associated with survival in non-metastatic STSs patients [16-18]. However, our study showed that age was not an independent risk factor of either OS or CSS, a trend toward an increased OS and CSS was observed for patients with age $<60$ years compared with those of age $\geq 60$ years. Abraham et al. [12] also reported that age was not an independent predictor of survival in patients with somatic LMS. We found that tumor location was not associated with either OS or CSS, but patients with upper limb tumor tend to have a worse median survival (Table 2). Tumor size was recognized as one of the important predictors of LMS $[14,15,19]$. We identified tumor size $>10 \mathrm{~cm}$ as an independent risk factor for decreased OS and CSS in metastatic extremity LMS population. Iqbal et al. [20] also reported that tumor size affected the survival in metastatic STS. Therefore, tumor size is an important prognostic factor for extremity LMS patients with or without metastasis at presentation. High histological grade is identified as an indicator of a poor prognosis in somatic LMS $[12,14]$. However, in our metastatic cohort, tumor grade was not significantly associated with survival in univariate analysis, suggesting that tumor grade did not affect the survival after metastasis.

Surgery, radiotherapy and systemic chemotherapy constitute the current treatments of LMS patients. However, the appropriate treatment for metastatic extremity LMS patients remains unknown. Surgical resection is considered as the main local treatment for extremity LMS patients and could prolong their survival $[1,21]$. In our cohort, surgical resection of primary tumors also prolonged the survival of metastatic extremity LMS patients. In patients with metastasis, removing the primary tumor can alleviate pain, improve quality of life, and prolong survival. Therefore, local surgery is an appropriate treatment for metastatic extremity LMS patients. Patients undergoing metastasectomy from STSs had significantly prolonged survival compared to those patients with unresectable metastases [13, 22]. Therefore, for such patients, both primary and metastatic lesions should be actively treated in order to obtain maximum survival time.

Chemotherapy-related toxicity was as considerable and generally higher for older STS patients. Some studies reported that chemotherapy showed no benefit in relapse-free survival or overall survival in STS patients [23, 24]. Therefore, the treatment for older extremity LMS patients remains a challenge. Mankin et al. [1] reported that chemotherapy had no impact on outcome but patients treated with surgery plus adjuvant therapy seemed to live longer than those treated with surgery alone. Kasper et al. [25] reported that chemotherapy was associated with improved relapse-free survival only in patients $\geq 30$ years. Recent studies revealed that chemotherapy improved survival of extremity STSs patients including leiomyosarcoma [26-29]. In our metastatic cohort, chemotherapy proved to be of significant prognostic value and resulted in superior survival, suggesting chemotherapy may be beneficial in prolonging survival of metastatic extremity LMS patients.

Radiotherapy can offer effective local control and reduce the local recurrence. Combination of surgery and perioperative RT is now widely adopted as the mainstream treatment for extremity STS [30, 31]. Massi et al. [19] reported that surgery in combination with radiation therapy, allowed the best chance of cure for soft tissue extremity. The effects of 
radiotherapy on survival of metastatic extremity LMS patients are rarely studied. Our univariate analysis revealed that radiation treatment was not significantly associated with either OS or CSS. Harati et al. [14] also found that radiation did not significantly improve local recurrence-free survival, disease-specific survival in somatic LMS. However, van Cann et al. [32] reported that metastatic LMS patients undergoing radiation treatment had significant better survival compared to patients not undergoing this treatment. Thus, prospective trials are urgently required for further confirmation.

Finally, this study has several limitations. First, the SEER database does not include information about local recurrence or metastasis during follow-up, which may affect the prognosis. Second, other known prognostic factors in cancer survival such as surgery or chemotherapy procedures, were not available in this database. Despite these shortcomings, the SEER database provides important insights into rare cancers, such as extremity soft tissue LMS and metastatic disease at diagnosis.

\section{Conclusion}

This is the largest population-based study to describe the demographics and analyze the prognosis for 239 patients with soft tissue extremity LMS and metastasis at presentation. OS and CSS rates of the entire group at 3-year were $22.6 \%$ and $23.4 \%$, respectively. The median OS and CSS were 14.0 \pm 1.5 and 15.0 \pm 2.3 months, respectively. Tumor size, surgery, and chemotherapy were independently associated with survival outcome. This study provides data that may help clinicians to better understand the features and estimate the prognosis of patients with metastatic extremity LMS and to provide appropriate treatment recommendations.

\section{Funding}

This work was supported by Zhejiang Provincial Natural Science Foundation (Grant no. LQ17H060003) and Science and technology benefit for people of Ningbo (Grant no. 2016C51003).

\section{Competing Interests}

The authors have declared that no competing interest exists.

\section{References}

1. Mankin HJ, Casas-Ganem J, Kim JI, Gebhardt MC, Hornicek FJ, Zeegen EN. Leiomyosarcoma of somatic soft tissues. Clinical orthopaedics and related research. 2004; 421:225-31.

2. Gustafson P. Soft tissue sarcomaEpidemiology and prognosis in 508 patients. Acta Orthopaedica Scandinavica Supplementum. 1994; 259: 1-31.

3. Fletcher CDM, Unni KK, Mertens F. World Health Organization Classification of Tumours. Pathology and Genetics of Tumours of Soft Tissue and Bone. Lyon, France: International Agency for Research on Cancer publisher; 2002.
4. Weiss SW. Smooth muscle tumors of soft tissue. Advances in anatomic pathology. 2002; 9: 351-9.

5. Grossmann AH, Layfield LJ, Randall RL. Classification, molecular characterization, and the significance of pten alteration in leiomyosarcoma. Sarcoma. 2012; 2012: 380896.

6. Miettinen M, Fetsch JF. Evaluation of biological potential of smooth muscle tumours. Histopathology. 2006; 48: 97-105.

7. Van Glabbeke M, van Oosterom AT, Oosterhuis JW, Mouridsen H, Crowther D, Somers R, et al. Prognostic factors for the outcome of chemotherapy in advanced soft tissue sarcoma: an analysis of 2,185 patients treated with anthracycline-containing first-line regimens--a European Organization for Research and Treatment of Cancer Soft Tissue and Bone Sarcoma Group Study. Journal of clinical oncology : official journal of the American Society of Clinical Oncology. 1999; 17: 150-7.

8. Coindre JM, Terrier P, Guillou L, Le Doussal V, Collin F, Ranchere D, et al. Predictive value of grade for metastasis development in the main histologic types of adult soft tissue sarcomas: a study of 1240 patients from the French Federation of Cancer Centers Sarcoma Group. Cancer. 2001; 91: 1914-26.

9. Bauer HC, Trovik CS, Alvegard TA, Berlin O, Erlanson M, Gustafson P, et al. Monitoring referral and treatment in soft tissue sarcoma: study based on 1,851 patients from the Scandinavian Sarcoma Group Register. Acta orthopaedica Scandinavica. 2001; 72: 150-9.

10. Serrano C, George S. Leiomyosarcoma. Hematology/oncology clinics of North America. 2013; 27: 957-74.

11. Ipach I, von Weyhern CH, Kopp HG, Kunze B, Kluba T. Extremity leiomyosarcoma metastasizing to the large bowel as a pedunculated colon polyp. Journal of clinical oncology : official journal of the American Society of Clinical Oncology. 2011; 29: e799-802.

12. Abraham JA, Weaver MJ, Hornick JL, Zurakowski D, Ready JE. Outcomes and prognostic factors for a consecutive case series of 115 patients with somatic leiomyosarcoma. The Journal of bone and joint surgery American volume. 2012; 94: 736-44.

13. Krishnan CK, Kim HS, Park JW, Han I. Outcome After Surgery for Extremity Soft Tissue Sarcoma in Patients Presenting With Metastasis at Diagnosis. American journal of clinical oncology. 2018; 41: 681-6.

14. Harati K, Daigeler A, Lange K, Niggemann H, Stricker I, Steinau HU, et al. Somatic Leiomyosarcoma of the Soft Tissues: A Single-Institutional Analysis of Factors Predictive of Survival in 164 Patients. World journal of surgery. 2017; 41: 1534-41.

15. Miyajima K, Oda Y, Oshiro Y, Tamiya S, Kinukawa N, Masuda K, et al. Clinicopathological prognostic factors in soft tissue leiomyosarcoma: a multivariate analysis. Histopathology. 2002; 40: 353-9.

16. Nishida Y, Tsukushi S, Nakashima H, Ishiguro N. Clinicopathologic prognostic factors of pure myxoid liposarcoma of the extremities and trunk wall. Clinical orthopaedics and related research. 2010; 468: 3041-6.

17. Hoven-Gondrie ML, Bastiaannet E, Ho VK, van Leeuwen BL, Liefers GJ, Hoekstra HJ, et al. Worse Survival in Elderly Patients with Extremity Soft-Tissue Sarcoma. Annals of surgical oncology. 2016; 23: 2577-85.

18. Bates JE, Dhakal S, Mazloom A, Constine LS. The Benefit of Adjuvant Radiotherapy in High-grade Nonmetastatic Retroperitoneal Soft Tissue Sarcoma: A SEER Analysis. American journal of clinical oncology. 2018; 41: 274-9.

19. Massi D, Beltrami G, Mela MM, Pertici M, Capanna R, Franchi A. Prognostic factors in soft tissue leiomyosarcoma of the extremities: a retrospective analysis of 42 cases. European journal of surgical oncology : the journal of the European Society of Surgical Oncology and the British Association of Surgical Oncology. 2004; 30: 565-72.

20. Iqbal N, Shukla NK, Deo SV, Agarwala S, Sharma DN, Sharma MC, et al. Prognostic factors affecting survival in metastatic soft tissue sarcoma: an analysis of 110 patients. Clin Transl Oncol. 2016; 18: 310-6.

21. Bathan AJ, Constantinidou A, Pollack SM, Jones RL. Diagnosis, prognosis, and management of leiomyosarcoma: recognition of anatomic variants. Current opinion in oncology. 2013; 25: 384-9.

22. Putnam JB, Jr., Roth JA, Wesley MN, Johnston MR, Rosenberg SA. Analysis of prognostic factors in patients undergoing resection of pulmonary metastases from soft tissue sarcomas. The Journal of thoracic and cardiovascular surgery. 1984; 87: 260-8.

23. Woll PJ, Reichardt P, Le Cesne A, Bonvalot S, Azzarelli A, Hoekstra HJ, et al. Adjuvant chemotherapy with doxorubicin, ifosfamide, and lenograstim for resected soft-tissue sarcoma (EORTC 62931): a multicentre randomised controlled trial. The Lancet Oncology. 2012; 13: 1045-54.

24. Kang S, Kim HS, Kim S, Kim W, Han I. Post-metastasis survival in extremity soft tissue sarcoma: a recursive partitioning analysis of prognostic factors. European journal of cancer. 2014; 50: 1649-56.

25. Kasper B, Ouali M, van Glabbeke M, Blay JY, Bramwell VH, Woll PJ, et al. Prognostic factors in adolescents and young adults (AYA) with high risk soft tissue sarcoma (STS) treated by adjuvant chemotherapy: a study based on pooled European Organisation for Research and Treatment of Cancer (EORTC) clinical trials 62771 and 62931. European journal of cancer. 2013; 49: 449-56.

26. Pasquali S, Gronchi A. Neoadjuvant chemotherapy in soft tissue sarcomas: latest evidence and clinical implications. Therapeutic advances in medical oncology. 2017; 9: 415-29.

27. Movva S, von Mehren M, Ross EA, Handorf E. Patterns of Chemotherapy Administration in High-Risk Soft Tissue Sarcoma and Impact on Overall 
Survival. Journal of the National Comprehensive Cancer Network : JNCCN. 2015; 13: 1366-74.

28. Schliemann C, Kerkhoff A, Hesse P, Brockling S, Hardes J, Streitburger A, et al. Adjuvant chemotherapy-Radiotherapy-Chemotherapy sandwich protocol in resectable soft tissue sarcoma: An updated single-center analysis of 104 cases. 2018; 13(e): 0197315.

29. Tanaka K, Mizusawa J, Fukuda H, Araki N, Chuman H, Takahashi M, et al. Perioperative chemotherapy with ifosfamide and doxorubicin for high-grade soft tissue sarcomas in the extremities (JCOG0304). Japanese journal of clinical oncology. 2015; 45: 555-61.

30. Rosenberg SA, Kent H, Costa J, Webber BL, Young R, Chabner B, et al. Prospective randomized evaluation of the role of limb-sparing surgery, radiation therapy, and adjuvant chemoimmunotherapy in the treatment of adult soft-tissue sarcomas. Surgery. 1978; 84: 62-9.

31. MacNeill AJ, Gupta A, Swallow CJ. Randomized Controlled Trials in Soft Tissue Sarcoma: We Are Getting There! Surgical oncology clinics of North America. 2017; 26: 531-44.

32. van Cann T, Cornillie J, Wozniak A, Debiec-Rychter M, Sciot R, Hompes D, et al. Retrospective Analysis of Outcome of Patients with Metastatic Leiomyosarcoma in a Tertiary Referral Center. Oncology research and treatment. 2018; 41: 206-13. 